\title{
Evaluation and Outcome of Surgeon-Reported Incidents regarding Surgical Patient Safety
}

\author{
Takanori Ayabe ${ }^{1,2^{*}}$, Masaki Tomita1, Manabu Okumura ${ }^{2}$, Ryo Maeda1, Kunihide Nakamura ${ }^{2,3}$ \\ ${ }^{1}$ Department of Surgery, Faculty of Medicine, Division of Thoracic and Breast Surgery, University of Miyazaki, Miyazaki, Japan \\ ${ }^{2}$ Division of Medical Safety Management, University of Miyazaki, Miyazaki, Japan \\ ${ }^{3}$ Department of Surgery, Division of Cardiovascular Surgery, University of Miyazaki, Miyazaki, Japan \\ Email: ^tayabe@med.miyazaki-u.ac.jp
}

How to cite this paper: Ayabe, T., Tomita, M., Okumura, M., Maeda, R. and Nakamura, K. (2018) Evaluation and Outcome of Surgeon-Reported Incidents regarding Surgical Patient Safety. Surgical Science, 9, 422-445.

https://doi.org/10.4236/ss.2018.911049

Received: August 6, 2018

Accepted: November 24, 2018

Published: November 27, 2018

Copyright (c) 2018 by authors and Scientific Research Publishing Inc. This work is licensed under the Creative Commons Attribution International License (CC BY 4.0).

http://creativecommons.org/licenses/by/4.0/

\begin{abstract}
Background: We retrospectively analyzed incident reports from surgeons to learn about surgical patient safety and improve surgical quality. Material and Methods: For the 10 years and 3 months between February 2007 and May 2017, 236 incident reports from surgeons were collected. The impact levels of the incidents for patients were represented by a degree of adverse influence to a patient (level 0, 1, 2, 3a, 3b, 4a, 4b, and 5). The outcome of the incident reports was evaluated by the profile, cause, surgery-relation, and factor. Results: The level of incidents resulted in level $0(\mathrm{n}=18,7.6 \%)$, level $1(\mathrm{n}=28$, $11.9 \%)$, level $2(\mathrm{n}=16,6.8 \%)$, level $3 \mathrm{a}(\mathrm{n}=44,18.6 \%)$, level $3 \mathrm{~b}(\mathrm{n}=94$, $39.8 \%)$, level $4 \mathrm{a}(\mathrm{n}=1,0.4 \%)$, level $4 \mathrm{~b}(\mathrm{n}=6,2.5 \%)$, level $5(\mathrm{n}=15,6.4 \%)$ and others $(\mathrm{n}=14,5.9 \%)$. The profiles of the surgery-related incidents $(\mathrm{n}=84)$ showed other unexpected events $(15.7 \%, \mathrm{n}=37)$, second surgery within 24 hours $(9.3 \%, \mathrm{n}=22)$, and unexpected excessive bleeding $(6.8 \%, \mathrm{n}=16)$. The cause of the surgery-related incidents involved hemorrhage $(n=45,53.6 \%)$. Except for complications and accidental diseases $(n=77,32.6 \%)$, the occurrence factor of the incidents cited factors of personal behavior $(\mathrm{n}=85$, $36.0 \%)$, human factors $(\mathrm{n}=37,15.7 \%)$, environmental equipment $(\mathrm{n}=6$, $2.5 \%)$, and others $(\mathrm{n}=31,13.1 \%)$. Conclusions: The perioperative incidents submitted by surgeons were comparatively proved to be a higher influence level for patients such as unexpected events or surgery and second surgery within 24 hours. An incident reporting system is crucial for surgeons to ensure both surgical patient safety and to improve surgical quality. An aggressive reporting attitude should become useful to enhance safety awareness on a facility-wide basis.
\end{abstract}

\section{Keywords}

Surgeon, Surgery, Incident, Patient Safety 


\section{Introduction}

With an estimated 1 million perioperative deaths globally occurring each year [1], surgical safety has emerged as a crucial health issue in the past two decades, requiring increased financial and research investments [2] [3] [4]. A surgical complication is any undesirable, unintended, and direct result of an operation affecting the patient that would not have occurred, had the operation gone; and could reasonably be expected [5]. Societal interest in surgical outcomes is expressed in the now-familiar Institute of Medicine report, "To Err Is Human", which detailed "unnecessary deaths resulting from surgical complications" [6]. In treating patients, the $21^{\text {st }}$ century health care system must adapt and increasingly focus upon the provision of care, that is, safe, effective, patient-centered, timely, efficient, and equitable [7]. Knowledge, technical skill, and judgement are the foundations of safe surgical care, but do not always preventing complications. Patients are frequently injured because of flaws in the design of medical systems. Increasingly, improvement is the results of team efforts in the form of surgical collaboratives, rather than individual technical brilliance.

The ethics of surgical complications can be described in the framework of the "Four Principles" approach to medical ethics, including respect for patient autonomy, beneficence, nonmaleficence and justice [8] [9]. The stress of responsibility for patient outcomes including complications has also been emphasized. For both the surgeon and the patient, a system of surgical accountability that focuses on blaming individuals has a poor prospect of significant improvement. Contemporary surgical morbidity and mortality conferences must reflect this realization. The prevention, reporting, analysis, and minimization of surgical harm can only occur in learning environments, not those of blame and reprisal. The moral imperative to improve patient care to the greatest extent humanly possible implies that surgical complications will remain a major focus area for surgeons.

As a realistic tool has an immediate effect for the management of patient safety in a hospital, an incident-reporting system is widely being used in medical institutions in Japan [10]. The significance of the reporting is that many more incidents sent to the division of medical safety management are summarized by the following five items: 1) securing patient safety, that is, hospital executive and head can grasp and intervene in the reported adverse event as soon as possible; it is possible for a multidisciplinary team to perform the best treatment and care for the patient at cross-department; 2) to share the facts of incidental and accidental events; that is, at the time of reporting and submitting an incident report, a hospital organization can consider not only the issue of an individual and/or single department, but also the problems of hospital jurisdiction; 3) to secure transparency, that is, submitting an incident report, at least, at that time, they disclose evidence of no vicious hiding and no ill will; 4) to receive formal support from hospital top management, that is, not only the supporting of medical treatment and care, but also receiving the full support from the hospital organi- 
zation, if the reported incident case might have developed a disputed issue; and 5)to improve the hospital healthcare system, that is, it is possible to perform a systematic improvement and reduce defects inside the hospital.

However, generally, there are relatively fewer numbers of doctor's reports of incidents compared to those from other personnel such as nurses. In an operating room, the surgeons and anesthesiologists have taken little care of the responsibility about an accident and incident, and also, they aim for intraoperative and postoperative safe surgery in order to be able to discharge patients. In that situation, although they are known to be very busy, however, it is considered to be very important, novel, good attitude to report incidents. The World Health Organization has focused on surgical care specifically through a separate effort referred to as the "Safe Surgery Save Lives" campaign. One very tangible result of this effort is the Surgical Checklist [11]. It is now being tested in eight countries; the vision is that a standardized forum for intraoperative communication will be internationally adopted. We have already evaluated the effectiveness of the surgical check list implemented in a university hospital in Japan and we could confirm its importance and usefulness [12].

The terms quality and safety have important bearings on any discussion of patient care. These are related subjects but have different meanings, and these differences should be underscored before any dialogue about patient safety begins. Safety means "freedom from harm"; in the context of patient care, "safety" mean freedom from harm associated with any medical action or treatment. Quality is a more global term referring to a "degree of excellence". It is theoretically possible for a hospital to be safe, but with an average or poor quality. However, it is not possible for a hospital to be of high quality and unsafe. In performing very high risk surgery, it should be considered to be difficult and important to maintain a balance of high quality and safety during surgery.

It becomes an important goal for surgeons to improve the quality of care by minimizing surgical complications and adverse events. Surgeons should collect and analyze past similar incident cases from their reporting system and should categorize them to perform problem-solving, and as a result, they can improve their surgical quality. We significantly focus on the subject of patient safety in surgery, and then retrospectively analyze surgical incidental experiences with complications. Although we collected data from a single university hospital, we studied the surgeon-reported incidents and their results. We tried to clarify their features and to evaluate the outcomes of the surgical incidents, and we want to use the obtained novel experience for future development in the surgical field.

\section{Materials and Methods}

\subsection{Collection of Incident Reports}

For 11 years and 3 months between February 2007 and May 2017, we collected 236 incidents reported by surgeons of our facility. The breakdown of the reported divisions was by Thoracic Surgery $(\mathrm{n}=42,17.8 \%)$, Cardiovascular Sur- 
gery ( $\mathrm{n}=61,25.8 \%)$, and Hepato-Biliary-Pancreatic, Digestive, Endocrine, and Pediatric Surgery $(n=133,56.4 \%)$. The level classification of incidents was based on the guidelines developed by the Council of Medical Safety Management of National University (Table 1). This study was approved by the University of Miyazaki Hospital Clinical Research Ethics Board (No. 2015-129).

\subsection{Range of the Reported Incidents Recommended for Medical Safety Management in Our University Hospital}

\subsubsection{Subject of Incidents}

The incidents are summarized into three categories: 1) situation of an occurrence of injury to a patient (except for the items described in "2.2.2. Exclusion of subject of incidents"), 2) situation of the possible occurrence of injury to a patient, and 3) claim from the patients and the family (which is related to medical treatment).

For situations of 1) and 2), they deal with the failure of medical equipment (medical materials and instruments), tumbles and falls, suicide and suicide attempts, leaving without permission, medication mistakes of patient's self-management drugs, and patient needlestick.

Even if complications were suggested, the medical staff should report unexpected complications, "hiyari-hatt" (the word is Japanese, similar word meaning near-miss) of the medical staff, results of severe adverse events, complication events that could not be denied as a delayed discovery, delayed correspondence, and delayed treatment.

Table 1. The classification of the level of incident (Council of Medical Safety Management of National University Hospital).

\begin{tabular}{|c|c|c|c|}
\hline$\frac{\text { level of influence }}{\text { (a time-point of report) }}$ & $\begin{array}{l}\text { Continuity of } \\
\text { injury }\end{array}$ & Degree of injury & Contents \\
\hline Level 1 & none & - & $\begin{array}{l}\text { There was no actual harm (there could not be denied to affect some influences to the } \\
\text { patients). }\end{array}$ \\
\hline Level 2 & Temporarily & Mild & $\begin{array}{l}\text { There was no medical treatment and cares (enhancement of patient-observation, mild } \\
\text { changes of vital sign, necessity of medical examination to confirm a patient safety). }\end{array}$ \\
\hline Level 3a & Temporarily & Moderate & $\begin{array}{l}\text { There needed to perform simple care and medical treatment (disinfection, wet cloth, } \\
\text { skin suture, medication of painkiller). }\end{array}$ \\
\hline Level 3b & Temporarily & Severe & $\begin{array}{l}\text { There needed to perform rich care and medical treatment (severe changes of vital sign, } \\
\text { necessity of respirator, surgery, extended duration of hospitalization, admission of } \\
\text { outpatients, bone fractures). }\end{array}$ \\
\hline Level 4a & Permanent & Mild to moderate & $\begin{array}{l}\text { Permanent disorders and after effects have not remained, however, it was not } \\
\text { accompanied by significant functional disorders and cosmetic problems. }\end{array}$ \\
\hline Level $4 b$ & Permanent & $\begin{array}{l}\text { Moderate to } \\
\text { severe }\end{array}$ & $\begin{array}{l}\text { Permanent disorders and after effects remained, however, there was accompanied by } \\
\text { significant functional disorders and cosmetic problems. }\end{array}$ \\
\hline Level 5 & Death & - & Death (except for natural course of primary disease). \\
\hline Others & - & - & - \\
\hline
\end{tabular}

The above incidents includes which were occurred by force majeure, mistake, and unexpected events. 


\subsubsection{Exclusion of Subject of Incidents}

The exclusion of the subject of incidents is described as follows: hospital-acquired infections, food poisoning cases, needle stick injury by staff member, violence and bodily injury cases, robbery cases, claim from the patient and the family (non-related to medical treatment), and natural course of primary disease. These items are excluded because another reporting system has been developed by the Council of Medical Safety Management of National University.

\subsection{Incidental Items Recommended to Be Reported to the Department of Operation Room}

For the department of operation room, incidental items recommended to be reported include mistaken patient identify, incorrect surgical site, intraoperative death, intraoperative cardiac arrest, surgery without obtaining informed consent, unscheduled surgery (especially surgery without informed consent), incorrect surgery, unexpected extension of a scheduled operating time ( $>6$ hours, consumption of more than two times the scheduled time), unexpected excessive hemorrhage $(\geq 5000 \mathrm{ml})$, admission to the intensive care unit, death within postoperative 48 hours, nerve injury, dermopathy (burns, bedsores, etc.), foreign body remaining in situ (surgical instrument, remnant, surgical sponge and gauze), intraoperative rupture of surgical instrument, occurrence of an accident due to failure of medical equipment, occurrence of an accident due to medical equipment (an improper operation), unexpected contamination of operating field and clean area, physical damage during tracheal intubation and extubation, anesthetic accident connected to certain death crisis of life, extension of postoperative awakening from anesthesia ( $>4$ hours), accident involving drug administration and instillation, accident involving blood transfusion, missing of resected specimen, misidentification of resected specimen, patient injury during transportation and transfer, intraoperative discovery of foreign body, defective surgery application, and other unexpected events.

\subsection{Incidental Items Recommended to Report in Inpatient and Outpatient Wards}

In the inpatient and outpatient wards, incidental items recommended for reporting include mistaken patient identify, medication error, incorrect examination (involving drawing blood), incorrect treatment, and occurrence of accident due to inadequate instruction (oral instruction); also, unexpected extension of examination and therapy, treatment time (>two times the scheduled time), unexpected excessive hemorrhage during examination and therapy, treatment (required for blood transfusion), postponement and cancellation of surgery due to influence of drug administration, examination, therapy, and treatment. Also included is nerve injury, dermopathy (burns, bedsores, etc.), tumble and falls (accidents due to imperfect informed consent). Also corruption of the medical equipment during examination and treatment, accidents due to the failure of the medical equipment, accidents due to improper operation and/or setup mistakes 
of medical equipment. Physical damage during tracheal intubation and extubation, physical damage during gastric lavage, and physical damage during cardiopulmonary resuscitation are also included along with accidents of artificial respiration, accidental extubation and or self-extubation of drain or tube. Also, accidental pollution of clean regions, accident during blood transfusion, poor documentation in medical records, actions of self-harm, suicide, and suicide attempt. Also, lost and damage of patient belongings (medications brought in, dentures, outfits, glasses), violence by fellow patient, sexual harassment, and other unexpected events.

\subsection{Items of Analysis}

We investigated incidents reported by surgeons and their breakdown and ratio. The collected incident reports totalled 236, and analyzed by classification of the levels of incidents, profile, cause, place of occurrence, occurrence factors, occurrence scenes, presence or absence of surgical relationship, and presence or absence of explanation of incident occurrence. In these 236 reports, 107 cases $(45.3 \%, 107 / 236)$ were extracted involving incidents in surgery, and that 84 cases $(35.6 \%, 84 / 236)$ were surgery-related incidents.

\subsection{Statistical Analysis}

A statistical technique was used by the seven techniques for qualitative analysis, which are collectively called the seven tools for quality control (QC seven tools). To analyze the frequency of appearance of the incident levels, a Pareto chart was used from the QC seven tools, i.e., quality control. The data in this study were analyzed by breakdown of the stratified analysis, distribution of numbers, and ratio.

\section{Results}

\subsection{The Classification of the Level of the Reported Incidents}

Table 2 shows the breakdown of the 236 incidents. Figure 1 shows a Pareto diagram of the incident levels, which displays the frequency of reports and percent of reports by the level of the incidents. The influence levels were summarized as follows: level 0: 18; level 1: 28; level 2: 16; level 3a: 44; level 3b: 94; level 4a:1; level 4b: 6; and level 5: 15, and others: 14. As the most often surgeon-reported incidents, the first place was the level of $3 \mathrm{~b}$ (39.8\%) and the second was the level of $3 \mathrm{a}(18.6 \%)$.The incidents classified by a higher degree than that of level $3 \mathrm{~b}$ were about half of the total (49.2\%), which means better medical treatment and care for severe injuries.

\subsection{Profiles of the Incidents}

Table 3 shows the profile of the incidents. Figure 2 shows a Pareto diagram of the incident profiles. The first place was medical treatment and care $(59.7 \%$, $141 / 236)$, the second was medical examination $(15.3 \%, 36 / 236)$, the next was 
Table 2. The classification of the level of the incident.

\begin{tabular}{ccc}
\hline Level & Cases $(\mathrm{n}=236)$ & $\%$ \\
\hline 0 & 18 & 7.6 \\
1 & 28 & 11.9 \\
2 & 16 & 6.8 \\
$3 \mathrm{a}$ & 44 & 18.6 \\
$3 \mathrm{~b}$ & 94 & 39.8 \\
$4 \mathrm{a}$ & 1 & 0.4 \\
$4 \mathrm{~b}$ & 6 & 2.5 \\
5 & 15 & 6.4 \\
Others & 14 & 5.9 \\
$\geq$ Level 3b & 116 & 49.2 \\
\hline
\end{tabular}

Table 3. The profile of the incidents.

\begin{tabular}{ccc}
\hline Profile & Cases $(\mathrm{n}=236)$ & $\%$ \\
\hline Medical treatment and care & 141 & 59.7 \\
Medical examination & 36 & 15.3 \\
Drug administration & 15 & 6.4 \\
Drain and tube & 14 & 5.9 \\
Giving instructions & 10 & 4.2 \\
Medical equipment & 7 & 3.0 \\
Blood transfusion & 3 & 1.3 \\
Nursing care & 2 & 0.8 \\
Unknown & 8 & 11.4 \\
\hline
\end{tabular}

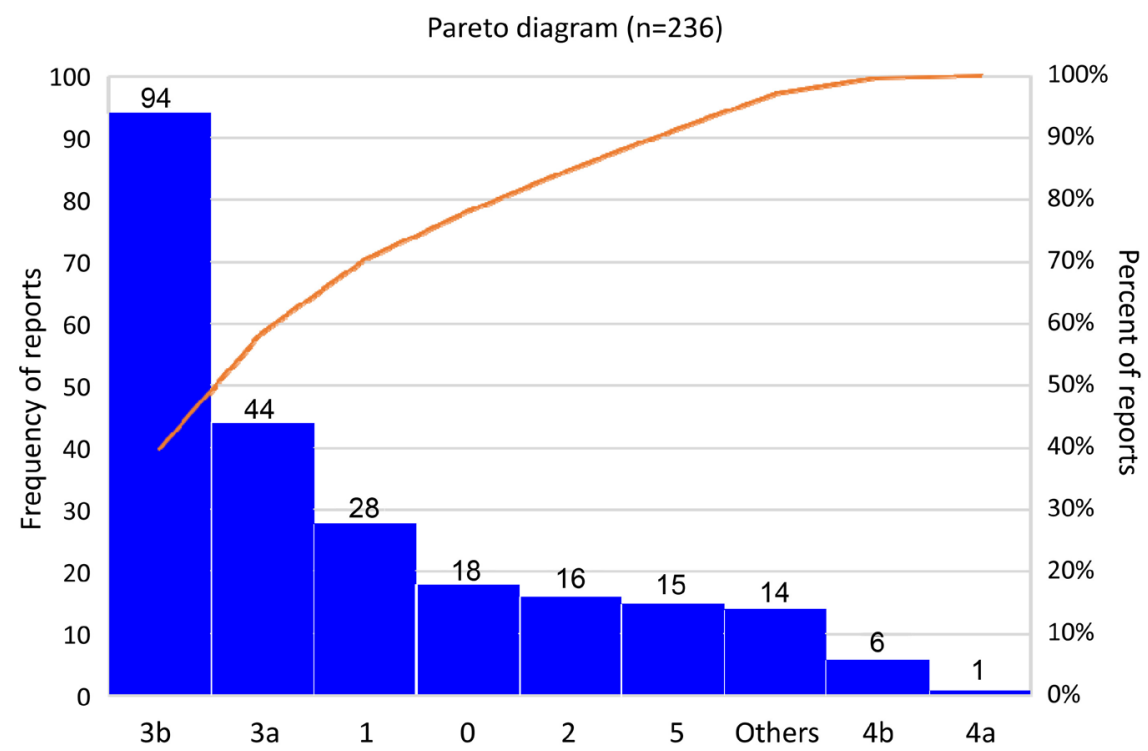

Figure 1. Pareto diagram of incident levels. 


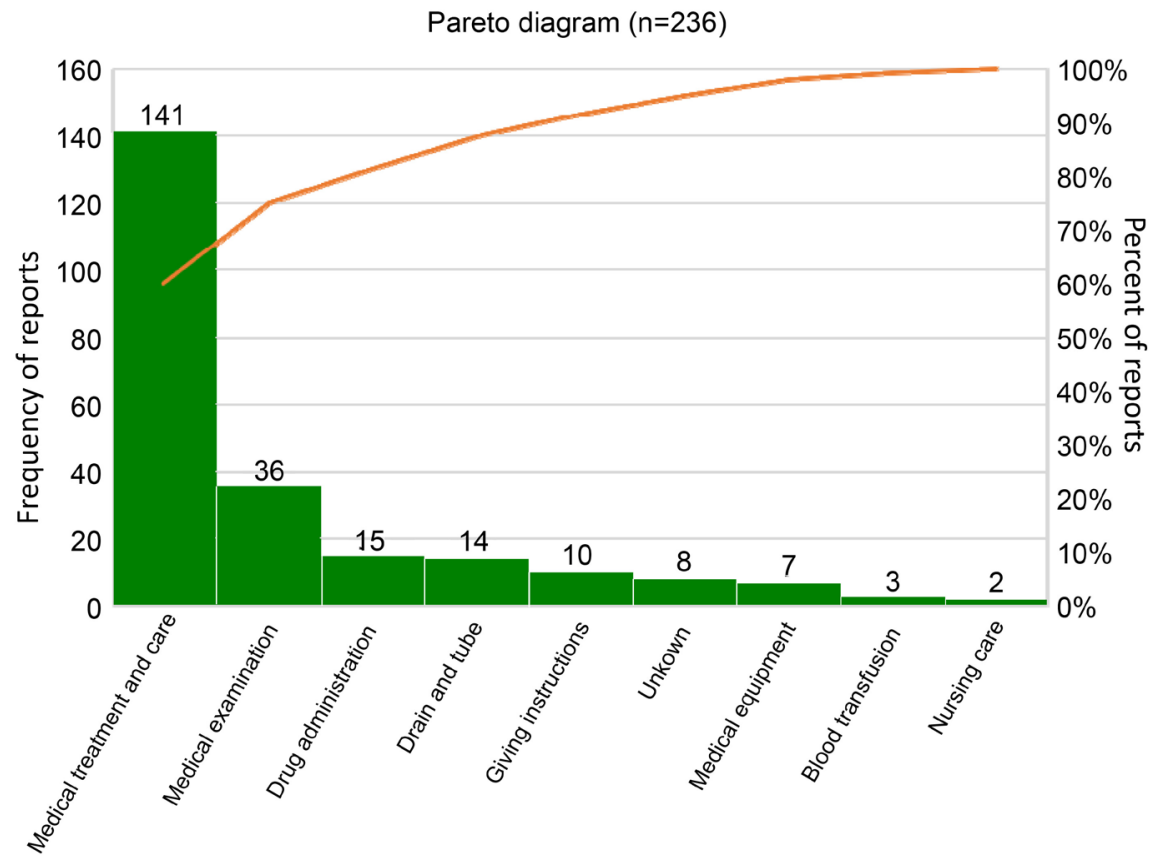

Figure 2. Pareto diagram of incident profile.

drug administration $(6.4 \%, 15 / 236)$, and drain and tube $(5.9 \%, 14 / 236)$, giving instructions $(4.2 \%, 10 / 236)$, medical equipment $(3 \%, 7 / 236)$, blood transfusion $(1.3 \%, 3 / 236)$, nursing care $(0.8 \%, 2 / 236)$, and unknown $(11.4 \%, 8 / 236)$. The medical treatment and care and medical examination involved three-quarters of the total.

Surgeons should know the profiles of the incidents, that is, they should know that almost all incidents were related to the medical treatment and care and the medical examination.

\subsection{The Causes of the Incidents}

Table 4 shows causes of the incidents. Figure 3 shows a Pareto diagram of the incident causes. The first place was order $(27.1 \%, 64 / 236)$, the second was medical examination $(17.4 \%, 41 / 236)$, the third was treatment and care $(14.4 \%$, $34 / 236)$, the fourth was medical materials $(8.9 \%, 21 / 236)$, and the fifth was medication $(7.6 \%, 18 / 236)$. The next places were medical equipment $(2.1 \%, 5 / 236)$, heat injury $(1.3 \%, 3 / 236)$, and consent documents $(1.3 \%, 3 / 236)$, and tumbles $(0.4 \%, 1 / 236)$. This order is observed in most of the incidents.

Surgeons should know the cause of the incidents; that is, when they should take care when ordering, performing the medical examination, and treatment care.

\subsection{The Places Where the Incidents Occur}

Table 5 shows the breakdown of the places where the incidents take place. Figure 4 shows a Pareto diagram of the incident occurrence places. The first place was the operating room $(37.7 \%, 89 / 236)$, the second place was the patient room 
Table 4. The causes of the incidents.

\begin{tabular}{rrr}
\hline Causes & Cases $(\mathrm{n}=236)$ & $\%$ \\
\hline Order & 64 & 27.1 \\
Medical examination & 41 & 17.4 \\
Treatment and care & 34 & 14.4 \\
Medical materials & 21 & 8.9 \\
Medication & 18 & 7.6 \\
Medical equipment & 5 & 2.1 \\
Heat injury & 3 & 1.3 \\
Consent document & 3 & 1.3 \\
Tumble & 1 & 0.4 \\
The other of lots of things & 46 & 9.5 \\
\hline
\end{tabular}

Table 5. The places where the incidents occur.

\begin{tabular}{rrr}
\hline The places where the incidents occur & Cases $(\mathrm{n}=236)$ & $\%$ \\
\hline Operating room & 89 & 37.7 \\
Patient room & 60 & 25.4 \\
Intensive care unit & 34 & 14.4 \\
Hospital ward & 7 & 3 \\
Outpatient treatment room & 3 & 1.3 \\
Patient lavatory & 1 & 0.4 \\
Hospital corridor & 1 & 0.4 \\
Others & 41 & 17.4 \\
Department of radiology & 6 & 2.5 \\
Department of optical diagnosis and treatment & 14 & 5.9 \\
Others & 21 & 8.9 \\
\hline
\end{tabular}

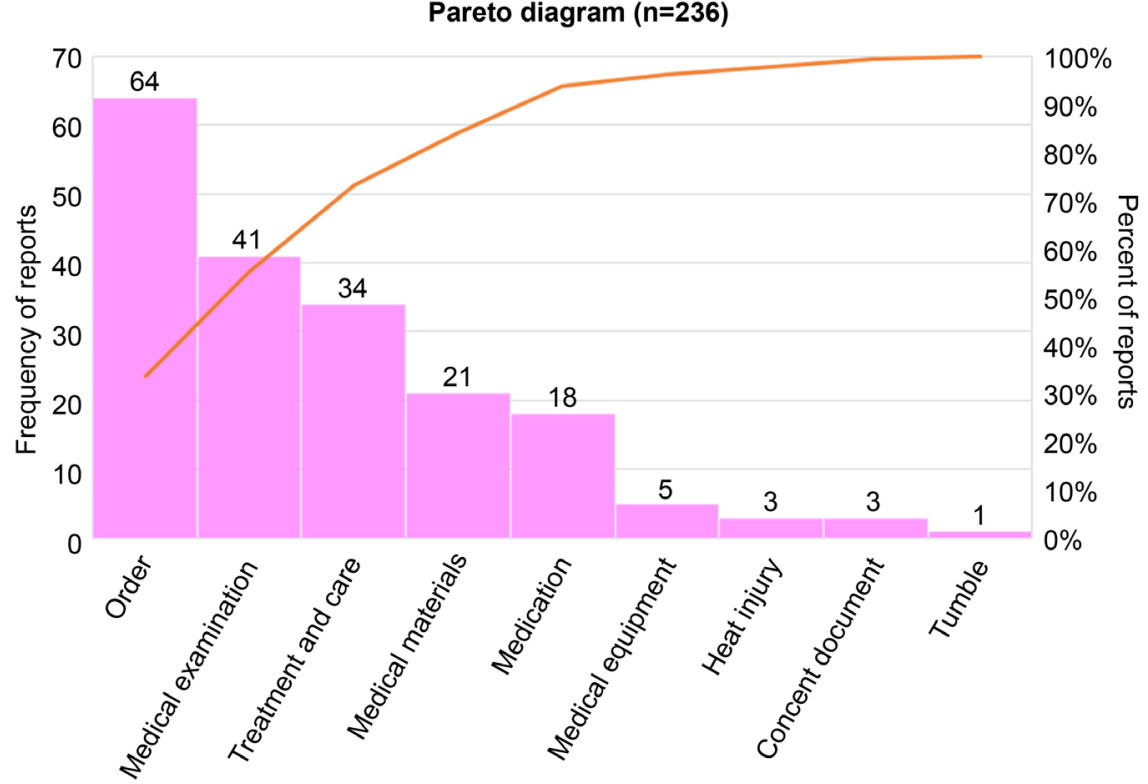

Figure 3. Pareto diagram of incident cause. 


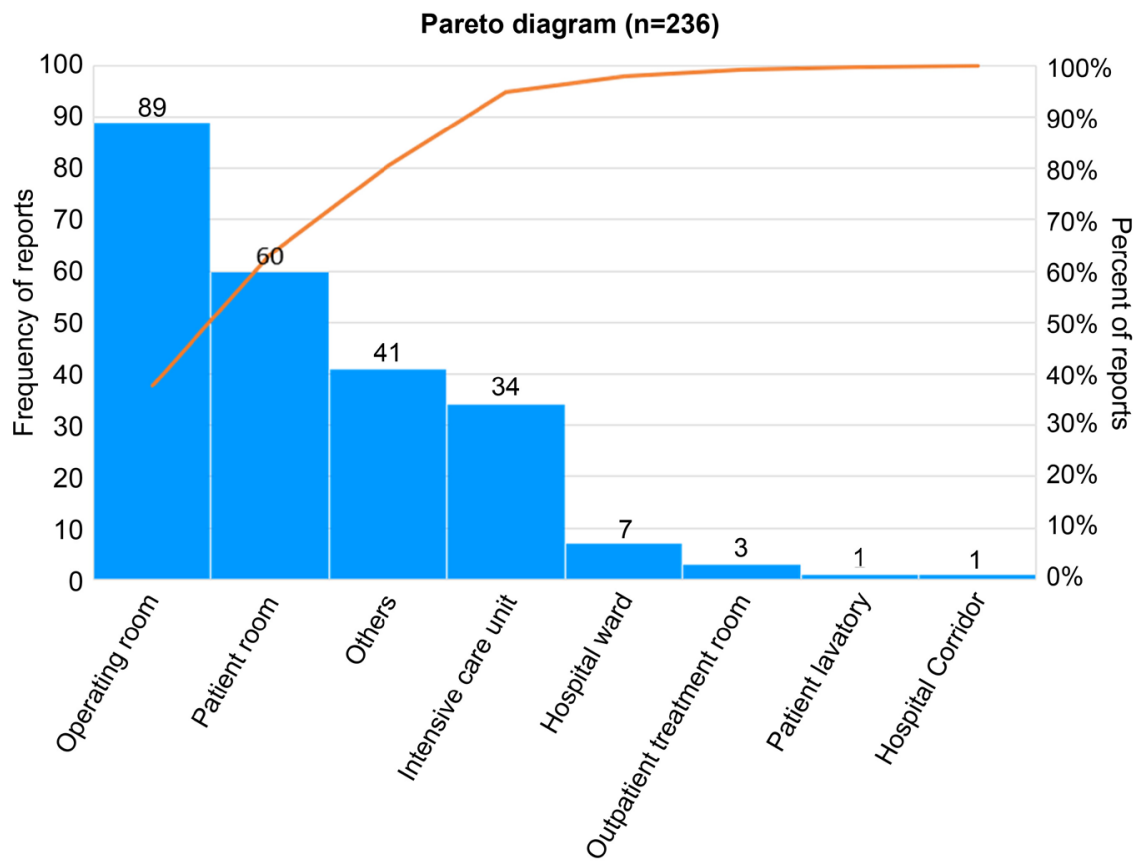

Figure 4. Pareto diagram of incident locations.

(25.4\%, 60/236), and the third place was the intensive care unit (14.4\%, 34/236). The next places were the hospital ward $(3.0 \%, 7 / 236)$, outpatient treatment room $(1.3 \%, 3 / 236)$, restroom $(0.4 \%, 1 / 236)$, corridor $(0.4 \%, 1 / 236)$, and others $(17.4 \%$, $41 / 236)$ which are the department of radiology $(2.5 \%, 6 / 236)$, department of endoscopic diagnostics and therapeutics $(5.9 \%, 14 / 236)$, others $(8.9 \%, 21 / 236)$. Because of the surgeon-reported incidents, it was natural that the operating room was the most common of the occurrence places.

Surgeons should know the occurrence place of the incidents, that is, almost all incidents occurred in the operating room, patient room, and intensive care units.

\subsection{The Occurrence Factors of the Incidents}

Table 6 shows the occurrence factors of the incidents. Figure 5 shows a Pareto diagram of the incident occurrence factor. By analysis of the occurrence factors of the incidents, Table 6 shows the complications and accidental disease (32.6\%, $77 / 236)$, personal behavior $(36.0 \%, 85 / 236)$, human factor $(15.7 \%, 37 / 236)$, environment equipment $(2.5 \%, 6 / 236)$, and others $(13.1 \%, 31 / 236)$. The complications and accidental disease occupied one-third of the total. Regarding the personal behavior, the first place was confirmation error $(24.6 \%, 58 / 236)$, the second place was judgment error $(6.4 \%, 15 / 236)$, and the next places were observation error $(1.7 \%, 4 / 236)$, lack of explanation $(1.7 \%, 4 / 236)$, insufficient cooperation $(0.8 \%, 2 / 236)$, and recording deficiencies $(0.8 \%, 2 / 236)$. Regarding the human factor, the first place was immature technique and procedure $(10.6 \%$, $25 / 236)$, while the next places were lack of knowledge $(2.5 \%, 6 / 236)$, usually with 
Table 6. The occurrence factors of the incidents.

\begin{tabular}{|c|c|c|}
\hline Occurrence factors & Cases $(\mathrm{n}=236)$ & $\%$ \\
\hline Complications, accidental disease & 77 & 32.6 \\
\hline Personal behavior & 85 & 36.0 \\
\hline Confirmation error & 58 & 24.6 \\
\hline Judgment error & 15 & 6.4 \\
\hline Observation error & 4 & 1.7 \\
\hline Lack of explanation & 4 & 1.7 \\
\hline Insufficient cooperation & 2 & 0.8 \\
\hline Recording deficiencies & 2 & 0.8 \\
\hline Human factor & 37 & 15.7 \\
\hline Immature technique and procedure & 25 & 10.6 \\
\hline Lack of knowledge & 6 & 2.5 \\
\hline Usually with different body conditions & 5 & 2.1 \\
\hline Complicated work situation & 1 & 0.4 \\
\hline Environment equipment & 6 & 2.5 \\
\hline Problem of medical equipment & 4 & 1.7 \\
\hline Problem of drugs & 1 & 0.4 \\
\hline Problem with the system & 1 & 0.4 \\
\hline Others & 31 & 13.1 \\
\hline
\end{tabular}

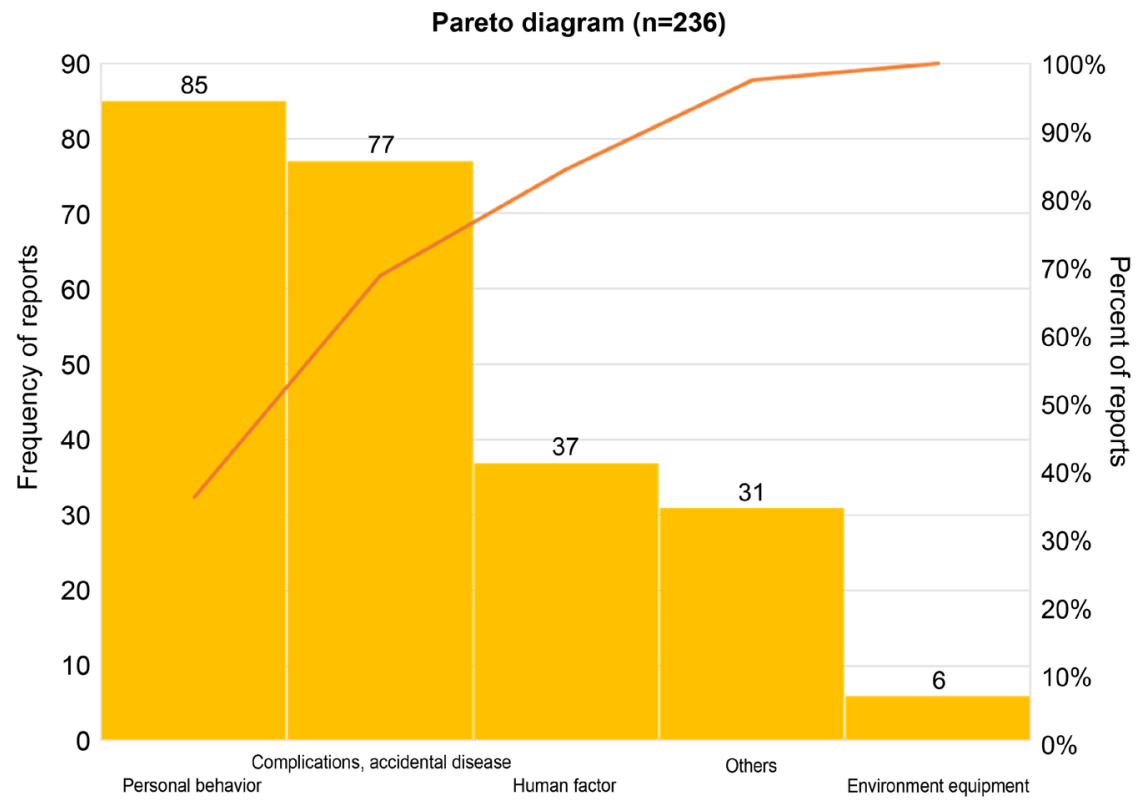

Figure 5. Pareto diagram of incident occurrence factor.

different body conditions $(2.1 \%, 5 / 236)$, and complicated work situation $(0.4 \%$, 1/236). Regarding the environment equipment, the first place was a problem with the medical equipment $(1.7 \%, 4 / 236)$, and the next places were problem of 
drugs $(0.4 \%, 1 / 236)$, and problem with the system $(0.4 \%, 1 / 236)$.

Surgeons should report their surgical complications and accidental diseases. Surgeons should take care of their personal behavior, especially, regarding the confirmation and judgment errors. For the immature technique and procedure, surgeons should increase their surgical technical skills.

\subsection{The Locations of the Incidents}

Table 7 shows the locations of the incidents. Figure 6 shows a Pareto diagram of the incident locations. The first place for the loation of the incidents was that the vast majority existed during surgery $(45.3 \%, 107 / 236)$. The next locations were specimen collection and reception $(7.6 \%, 18 / 236)$, other treatment $(5.5 \%, 13 / 236)$, and general treatment $(5.1 \%, 12 / 236)$. The rest involved treatment and medication $(5.1 \%)$, endoscopic examination (3.8\%), functional examination $(2.5 \%)$, first-aid treatment $(2.1 \%)$, image examination $(1.3 \%)$, instruction by ordering system $(1.3 \%)$, locations of life $(0.8 \%)$, and preparation of medication $(0.8 \%)$.

Surgeons should know the locations of the incidents, that is, almost all the incidents naturally occurred during surgery, thus the surgeons should take care of their surgical safety during an operation.

\subsection{The Locations of Incidents during Surgery}

Figure 7 shows a Pareto diagram of the surgery-related incident profile.

Table 8 shows the locations of incidents during surgery $(45.3 \%, 107 / 236)$. The first place was laparotomy $(12.3 \%, 29 / 236)$, and the second was thoracotomy (10.6\%, 25/236). The next places were video-assisted surgery $(6.4 \%, 15 / 236)$, open heart surgery $(5.5 \%, 13 / 236)$, and postoperative treatment $(3.4 \%, 8 / 236)$.

Table 7. The locations of the incidents.

\begin{tabular}{ccc}
\hline The locations of the incidents & Cases $(\mathrm{n}=236)$ & $\%$ \\
\hline Surgery & 107 & 45.3 \\
Specimen collection and reception & 18 & 5.5 \\
Other treatment & 13 & 5.1 \\
General treatment & 12 & 5.1 \\
Treatment and medication & 12 & 3.8 \\
Endoscopic examination & 9 & 2.5 \\
Functional examination & 6 & 2.1 \\
First-aid treatment & 5 & 1.3 \\
Image examination & 3 & 1.3 \\
Instruction by ordering system & 3 & 0.8 \\
Location of life & 2 & 0.8 \\
Preparation of medication & 2 & 8.1
\end{tabular}




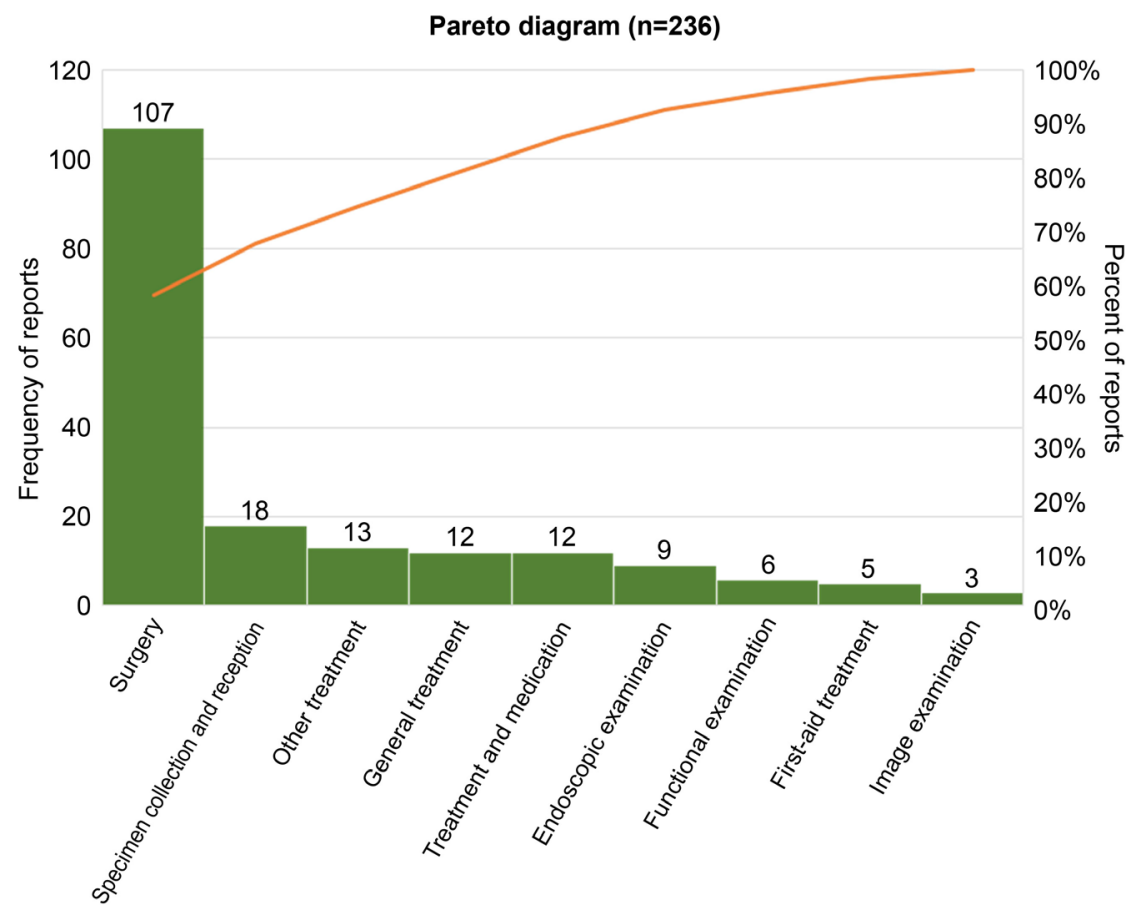

Figure 6. Pareto diagram of the incident location.

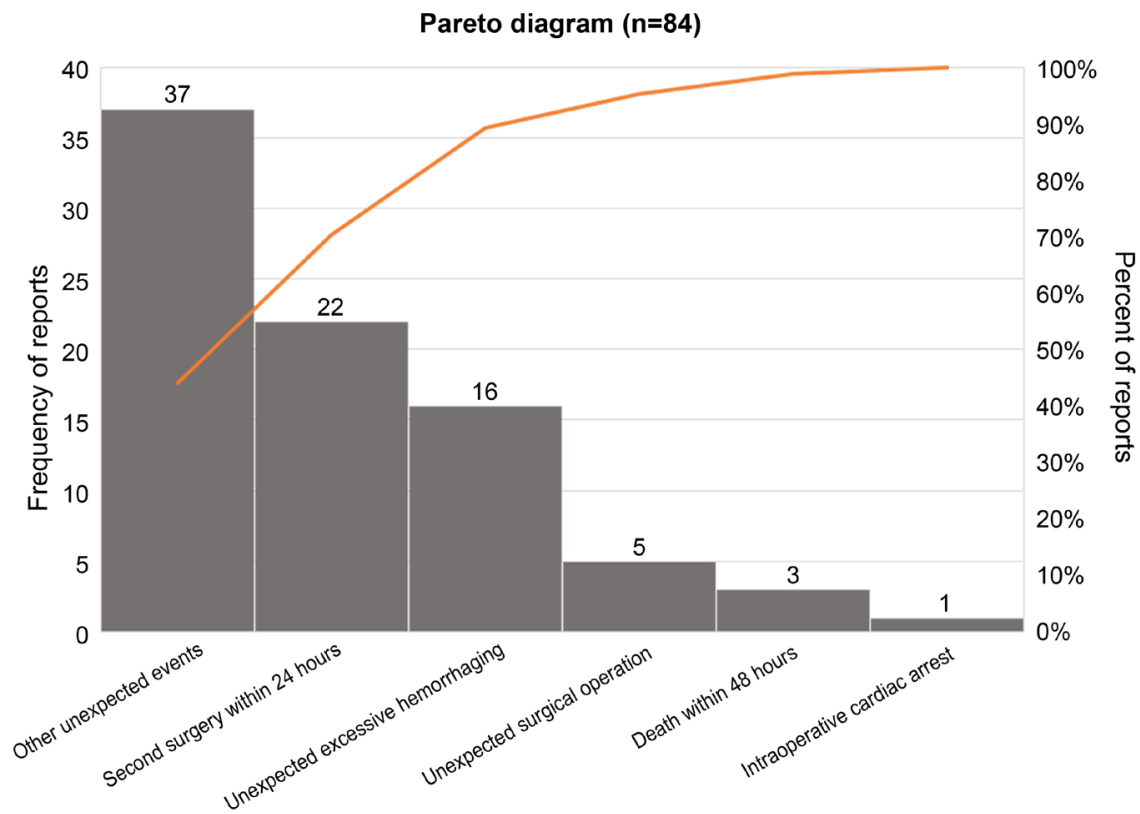

Figure 7. Pareto diagram of the surgery-related incident profile.

Surgeons should know the locations of the incidents during surgery, that is, almost all the incidents occurred during a laparotomy or thoracotomy.

\subsection{The Profile of Surgery-Related Incidents}

Table 9 shows the profile of the surgery-related incidents $(35.6 \%, 84 / 236)$. The surgery-related incidental events occupied one-third of the surgeon-reported 
Table 8. The locations of incidents during surgery (Breakdown of Surgery $n=107$ $(45.3 \%))$.

\begin{tabular}{ccc}
\hline The locations of incidents during surgery & Cases $(\mathrm{n}=107)$ & $\%$ \\
\hline Laparotomy & 29 & 12.3 \\
Thoracotomy & 25 & 10.6 \\
Video-assisted surgery & 15 & 6.4 \\
Open heart surgery & 13 & 5.5 \\
Other surgery & 9 & 3.8 \\
Postoperative treatment & 8 & 3.4 \\
Limbs & 1 & 0.4 \\
Others & 7 & 3.1 \\
\hline
\end{tabular}

Table 9. Profiles of the surgery-related incidents.

\begin{tabular}{ccc}
\hline Profile of the surgery-related incidents & Cases $(\mathrm{n}=84)$ & $\%$ \\
\hline The other unexpected events & 37 & 15.7 \\
Second surgery within 24 hours & 22 & 9.3 \\
Unexpected excessive hemorrhaging & 16 & 6.8 \\
Unexpected surgical operation & 5 & 2.1 \\
Death within 48 hours & 3 & 1.3 \\
Intraoperative cardiac arrest & 1 & 0.4 \\
\hline
\end{tabular}

incidents. The first place was the other unexpected events $(15.7 \%, 37 / 236)$, the second was second surgery within 24 -hours $(9.3 \%, 22 / 236)$, and the third was unexpected excessive hemorrhaging $(6.8 \%, 16 / 236)$. The next places were unexpected surgical operation $(2.1 \%, 5 / 236)$, death within 48 -hours $(1.3 \%, 3 / 236)$, and intraoperative cardiac arrest $(0.4 \%, 1 / 236)$.

Surgeons should take care of unexpected events during their surgery, that is, the prediction and anticipating are very important when they are performing an operation. When considering another method except for the standard procedure, that is, preventable treatment should be carefully considered. The complete confirmation of the bleeding point and complete hemostasis of the bleeding site should be important before closing wounds. During dealing with vessels and vascular branches, the operator should anticipate vascular injury and adapt for unexpected hemorrhages. Welfare manipulations are important. Surgeons should always be aware of surgical safety during an operation.

\subsection{The Presence or Absence of a Relationship between the Surgery and Incidents}

Table 10 shows the relationship between the surgery and incidents. The surgery-related events occupied one-half of the surgeon-reported incidents. The surgery-related incidents were observed in $128(54.2 \%, 128 / 236)$ cases and the non-surgery-related incidents were 108 (45.8\%, 108/236). Regarding the surgery-related incidents $(\mathrm{n}=128)$, intraoperative management was $75(31.8 \%$, 
Table 10. The presence or absence of a relationship between the surgery and incidents.

\begin{tabular}{rrr}
\hline Relationship between surgery and incidents & Cases $(\mathrm{n}=236)$ & $\%$ \\
\hline Surgery-related incidents & 128 & 54.2 \\
Intraoperative management & 75 & 31.8 \\
Postoperative management & 51 & 21.6 \\
Others & 2 & 1.6 \\
Non-surgery-related incidents & 108 & 45.8 \\
Postoperative management & 20 & 8.5 \\
Others & 88 & 81.5 \\
\hline
\end{tabular}

$75 / 236)$ and postoperative management was 51 (21.6\%, 51/236). In contrast, for the non-surgery-related incidents $(\mathrm{n}=108)$, postoperative management was 20 (8.5\%, 20/236).

Surgeons should take care of incidents using both intraoperative and postoperative managements.

\subsection{The Surgery-Related Factors of the Incidents (Hemorrhage, Organ Injury, and Vascular Occlusion)}

Table 11 shows the surgery-related factors of hemorrhage, organ injury, and vascular occlusion. Regarding the hemorrhages $(53.6 \%, 45 / 84)$, the first place was intraoperative bleeding $(25.9 \%, 21 / 84)$, the second place was postoperative bleeding $(21.4 \%, 18 / 84)$, in contrast, there were less observed incidents during the preoperative examination and preoperative treatment. Regarding organ injury $(19.0 \%, 16 / 84)$, the first place was nerves $(6.0 \%, 5 / 84)$, the second place was cardiovascular $(4.8 \%, 4 / 84)$, and the next places were lung and trachea $(2.4 \%$, $2 / 84)$, ureter $(2.4 \%, 2 / 84)$, skin $(1.2 \%, 1 / 84)$, intestinal tract $(1.2 \%, 1 / 84)$, and bile duct $(1.2 \%, 1 / 84)$. The vascular occlusion was observed in 7 incidents $(8.3 \%$, $7 / 84)$.

In order to perform surgical safety during an operation, surgeons should take care of hemorrhages, organ injury, and vascular occulusion.

\subsection{The Presence or Absence of Explanations of the Incident Occurrences}

Table 12 shows the presence or absence of explanations for the patient and family. The incident occurrence was explained in 110 (46.6\%, 110/236) and unexplained in $126(53.4 \%, 126 / 236)$ for the patients. On the other hand, the incident was explained in $75(31.8 \%, 75 / 236)$ and unexplained in $161(68.2 \%, 161 / 236)$ for the patient's family.

Based on an open disclosure, the attitude of surgeons should be to explain the incident occurrence during their surgery.

\section{Discussion}

Patient safety is a global public issue receiving rapidly increasing attention. Patient 
Table 11. The surgery-related factors of incidents.

\begin{tabular}{rrr}
\hline Surgery-related factors & $(\mathrm{n}=84)$ & $\%$ \\
\hline Hemorrhage-related incidents & 45 & 53.6 \\
Preoperative examination & 2 & 2.4 \\
Preoperative treatment & 4 & 4.8 \\
Intraoperative bleeding & 21 & 25.9 \\
Postoperative bleeding & 18 & 21.4 \\
Organ injury-related incidents & 16 & 19 \\
Nerve & 5 & 6.0 \\
Cardiovascular & 4 & 4.8 \\
Lung and trachea & 2 & 2.4 \\
Ureter & 2 & 2.4 \\
Skin & 1 & 1.2 \\
Intestinal tract & 1 & 1.2 \\
Bile duct & 1 & 1.2 \\
Vascular occlusion-related incidents & 7 & 8.3 \\
\hline
\end{tabular}

Table 12. The presence or absence of explanations of the incident occurrences.

\begin{tabular}{cccc}
\hline \multicolumn{2}{c}{ Explanation of incident occurrence } & Cases $(\mathrm{n}=236)$ & $\%$ \\
\hline Explanations for patient & Presence & 110 & 46.6 \\
& Absence & 126 & 53.4 \\
\multirow{2}{*}{ Explanations for patient's family } & Presence & 75 & 31.8 \\
& Absence & 161 & 68.2 \\
\hline
\end{tabular}

safety is the absence of avoidable harm inflicted on the patient through flaws in the healthcare systems [13]. Patient safety is an immature discipline compared with other fields of medical study. Assessing safety is more complicated than assessing the effectiveness of a new drug or accuracy of a novel diagnostic device as safety outcomes (surgical complications and other adverse events) are diverse and cannot be uniformly measured, and their incidences are too rare to be statistically stable in studies with a small sample size.

The important issues of errors and adverse outcomes in patient care have received attention in recent years as healthcare professionals become more focused on patient safety. Most studies of healthcare systems document an incidence of errors occurring in $3.5 \%-10 \%$ of hospitalized patients [14] [15]. A total of 51\% $77 \%$ of adverse events in hospitals are related to perioperative care [16]. A systemic review revealed that $14 \%$ of perioperative patients experience some form of adverse events, that $38 \%$ of these adverse events are preventable and $4 \%$ of patients experiencing adverse events have fatal outcomes [17]. In a 2008 review of in-hospital errors, Healthcare Grades cites a 5.5\% incidence of errors in surgical patients of which $29.1 \%$ resulted in fatalities [18]. Several studies have suggested 
that the proportion of preventable adverse events may be over 30\% [19] [20]. Most arise due to communication failure, poor records, clinician inexperience and poor discharge planning [20]. Improved reporting will ensure several improvements in the patient safety pathway by virtue of problem recognition; open cross-professional exchange, development of improved practice protocols and a strong peer-review mechanism. It has been argued that self-discussion by healthcare providers would be a good source for pro-actively encouraging error prevention [21].

In order to prevent errors and adverse outcomes, it is necessary to understand and anticipate the conditions that lead to errors [22]. The top error-producing conditions that are most important in surgical care are listed as fatigue/physiological degradation, faulty risk perception and stratification, high-risk/low-frequency event, time pressure, inadequate standardization, poor information transfer, "one-way decision gates" and plan continuation. The nature of surgical errors can be best characterized utilizing the Joint Commission standard nomenclature for the taxonomy of adverse outcomes. The most common error types and domain contributing to avoidable deaths in surgery fall into three major categories; i.e., 1) diagnosis, 2) treatment, and 3) prevention. In Gruen's analysis, $61 \%$ of the fatal errors were errors in treatment, $20 \%$ were errors in prophylaxis and prevention, $13 \%$ were errors in diagnosis, $5 \%$ errors in transport and transfer, and $1 \%$ were associated with equipment failure [23].

Elective surgery carries risks to patients for adverse outcomes. Each of the complex phases of surgical management introduces unique risks for errors with slightly different etiologies, that is, 1) initial assessment and diagnosis of surgical disease, 2) patient selection for surgery, 3) timing and plan of surgical intervention, 4) immediate preoperative care, 5) technical aspects of surgical procedure, 6) postoperative care, and 7) discharge and medication reconciliation. Krizek et al. [24] identified surgical errors and adverse events in 480 (45.8\%) of 1047 patients [24]. There were a total of 2138 incidents that included 164 (7.5\%) diagnostic errors (of which 5.2\% were judged to be serious, and 230 (10.5\%) errors that occurred during the surgical procedure (17.9\% serious) [24]. The root cause of these errors involves a combination of surgical competency, technical skill, team performance, communication and decision-making [25].

In Japan, in the field of patient safety and medical safety, there are some differences from the rest of the world. Incident, hiyari-hatt (in Japanese), medical accident, and medical malpractice are defined as listed below. During medical examination and treatment, an "incident" means an occurrence of deviated behavior and undesired situation, which were shifted from the ideal situation. A hiyari-hatt means a chilling, scary incident nearly missed event in everyday clinical work, which had not cause any injury to a patient. A "medical accident" harms a patient more than a certain level (level of influence is more than level $3 b$ ), which is described as follows: producing injury to the patient more than a certain level, that is defined as more than the level of influence which is more 
than level $3 b$, and there is a delinquency in the medical practice, which was defined as having a causal relationship. Table 1 shows a definition of the level of incident, which is defined by the Council of Medical Safety Management of National University Hospital in Japan. The above incidents occurred by force majeure, mistake, and unexpected events.

Surgeons should have to perform an invasive surgery in order to do a medical examination and treatment of a disease at a high-quality level. Patients have obtained informed consent to receive an examination and treatment and they expect an advantage from the invasive interventional treatment. On the other hand, patients might have problems from complications and adverse events. The patient and medical personnel have to consider the possibility of positives and negatives and their balance. They should understand and agree to undergo a risky surgery. During the process of the decision making, if there is some deviation between the patients understanding and explained skills of the medical side, when some bad conditions occur, such as there is a preoperative insufficient explanation, and an unexpected and impossible to foreseen adverse event occurred, trouble between the patients and doctors could produce the occurrence of complications and an adverse event. In addition to this situation, if some delay occurred in the diagnosis, medical examination, and start of the treatment, the trust relationship between the patient and doctor degrades, a situation that would be hard to fix. That is, the distrust of patients and their family increases, and poor and lack of communication, which causes the possibility of medical disputes. Although the medical staff intends to select the best appropriate therapy and care and intends to perform the best medicine for patients, however, complications and an adverse event can occur resulting in a bad outcome. If there is some added delay in the initial response and attitude for adverse events and complications, and if overlapping of other errors occur in these poor conditions, the hospital organization and the practical clinical scene might take the risk of litigation.

The operating room is one of the highest-risk areas for serious complications [26] [27], but little is known about the response of surgeons to serious complications, or how best to support the staff in the aftermath of adverse events. A recent survey study [28] of 7900 surgeons found that those who had experienced a surgical error during the past 3 months were more likely to have a lower quality of life, and increased probability of symptoms of burn-out and depression. Such effects are not only important for surgeons and their families, but also for their patients, as high levels of stress can adversely affect the clinical performance and patient safety [29] [30] [31] [32].

Performing surgery is an invasive practice, which has a definite risk, and some required complications cannot be avoided. As a postoperative complication, they range from some mild degrees to unavoidable severe and unexpected ones that occur with a certain probability. For example, in case of elderly patients with a poorer performance status and with severe preoperative complications, if 
surgeons performed extended invasive and long-time surgery, a high probability of postoperative complications should be able to be predicted. For example, postoperative pulmonary complications are an important contributor to surgical risk, occurring in an estimated $6.8 \%$ for all surgical patients [33]. Guidelines exist for assessing perioperative pulmonary risk and recommending preventive strategies for high-risk patients [34]. Respiratory failure, usually defined as unplanned intubation or prolonged ventilation, is considered to be the most serious of the respiratory complications because of its high morbidity, mortality, and associated costs [35]. If a surgical patient has an onset of postoperative pneumonia, it could be found during an early postoperative phase, and if a precise medication were started, it could be completely cured. However, there was some delay in the early-phase of pneumonia and in interventional medication, and also in addition to the lack of explanation, and poor prediction of prognosis of pneumonia and a certain probability, errors in management, small troubles and incidental events were increasing with postoperative complications. Although the adverse event was a complication, if there was some doubt among the patient, doctor and/or medical group, and in-hospital 3rd person, as an incident, it should be reported to the division of medical patient safety. The reason is that the hospital organization has to be notified of the incident as soon as possible. The incident will occur with a certain probability, which is an undesired and unexpected event. Based on medical safety behavior, human factor and hospital system, the incidents can be decreased, but they cannot reduce them to zero. A hospital organization should have response measures and support the medical staff group and definitely respond to the incident.

Retrospectively, we investigated the characteristics of the surgeon-reported incidents, and more than half of which were clarified as more than level $3 \mathrm{~b}$ (included $57.1 \%$ of the total) and more than half of the reported incidents were related to surgery (occupied $52.9 \%$ of all), which were related to intraoperative events (51.4\%), postoperative management (48.6\%), bleeding (56.8\%), and organ injury $(29.7 \%)$. The breakdown of the surgeries showed a second surgery within 24 hours (35.1\%), another unexpected event (21.6\%), performing of unscheduled operations (13.5\%), unexpected massive hemorrhage (8.1\%), and death within the postoperative 48 hours $(8.1 \%)$. If we experienced such incidents and accidents, we should consult the division of medical safety management in the hospital and submit an incident report, we should definitely perform an initial investigation, of which attitude will become important. For surgeons, not only the improvement of their personal surgical technical skill but also the total level of nontechnical skill of the surgical team is necessary to perform surgical safety and to improve surgical quality. A surgeon at the clinical site and in the operating room will have to concentrate and approach a difficult operation.

Our study was limited as, it was based on the retrospective investigation and analysis of the characteristics of surgical incident reports. There were local event number and their ratio, which were based on the small numbers of reports from 
limited surgeons. Although the surgical incidents were related to the perioperative term, however, there was a lack of detailed analyses, for example, we could not analyze the human factors and not solve problems of practical communication when performing surgery. We do not have a hospital organized system of Morbidity and Mortality $(M \& M)$ Conferences beyond clinical healthcare groups in patient safety to learn. The M \& M Conferences, "the golden hour" of surgery [36], is the primary and formal method for learning from errors in surgery. Results of a review of the M \& M Conferences in Medicine and Surgery indicate that error is more frequently addressed in surgery proceedings than in medicine proceedings [37]. Traditional surgery conference proceedings call for residents to present their surgical patients whose course of disease or injury resulted in surgical complications and/or death. These cases are often selected in advance by the conference leader, for their learning opportunities. The case presentation typically includes an overview of the patient's course of diagnosis and treatment, a literature review of the disease or procedure, categorization of the behavior that led to the complication or death, and questions and discussion by the audience members. The discipline and profession of surgery is respected for its long tradition of learning from optimal outcomes in the M \& M Conferences.

Surgical complications undoubtedly do arise, yet often they are not being reported back through the current adverse event reporting system. A likely explanation for this is that these complications are being routinely discussed at the monthly surgical morbidity and mortality ( $M$ \& $M$ ) meetings, thereby bypassing the adverse event reporting system. The goal of these $M \& M$ meetings is to learn from surgical errors, education of surgical staff and subsequently improve the quality of care [38].

In surgery, an intraoperative communication breakdown is the most important issue, which would produce a bad performance in surgery and the surgeons should had better know that situation. The reason is that breakdown in team communication is a major cause of error and near misses in medicine and surgery [39]-[44]. Surgeons have to manage conflict and strategies for conflict [45]. Task conflict is disagreement about how to complete a task or solve a problem, such as management of a patient's postoperative care. Interpersonal conflict is dissension that develops between two or more individuals and manifests itself in anger, frustration or friction. In our next future study, we would like to investigate the details of communication breakdown in surgery.

\section{Conclusion}

For surgeons, it becomes a very useful tool to submit incident reports, because the surgeons can retrospectively review a novel surgical experience by analyzing the surgical incidents and can improve their surgical quality. We retrospectively investigated surgical incidents reported by surgeons; they were found to contain many incidents more than the level $3 \mathrm{~b}$ related to a perioperative term, which was 
clarified by a second operation within 24 hours, unexpected event occurrence, and performing unplanned surgery. Without low morale, surgeons should have to provide a high-quality level and difficult surgical healthcare. It is important for a surgeon to properly understand and implement patient safety behavior and to have an appropriate open disclosure attitude. An aggressive reporting atmosphere and high-level patient safety system should be developed, and the breeding of a good safety culture will become important.

\section{Acknowledgements}

This work was supported by JSPS KAKENHI Grant Number JP18K04636.

\section{Conflicts of Interest}

The authors declare no conflicts of interest regarding the publication of this paper.

\section{References}

[1] Weiser, T.G., Makary, M.A., Haynes, A.B., Dziekan, G., Berry, W.R., Gawande, A.A. and Safe Surgery Saves Lives Measurement and Study Groups (2009) Standardised Metrics for Global Surgical Surveillance. The Lancet, 374, 1113-1117. https://doi.org/10.1016/S0140-6736(09)61161-2

[2] Dare, A.J., Grimes, C.E., Gillies, R., Greenberg, S.L., Hagander, L., Meara, J.G. and Leather, A.J. (2014) Global Surgery: Defining an Emerging Global Health Field. The Lancet, 384, 2245-2247. https://doi.org/10.1016/S0140-6736(14)60237-3

[3] Gutnik, L.A., Dielman, J., Dare, A.J., Ramos, M.S., Riviello, R., Meara, J.G., Yamey, G. and Shrime, M.G. (2015) Funding Flows to Global Surgery: An Analysis of Contributions from the USA. The Lancet, 385, S51. https://doi.org/10.1016/S0140-6736(15)60846-7

[4] Bickler, S.W. and Spiegel, D.A. (2008) Global Surgery-Defining a Research Agenda. The Lancet, 372, 90-92. https://doi.org/10.1016/S0140-6736(08)60924-1

[5] Katz, P. (1999) The Scalpel's Edge: The Culture of Surgeon. Allyn \& Bacon, Boston, MA.

[6] Bosk, C. (2003) Forgive \& Remember. 2nd Edition, University of Chicago Press, Chicago. https://doi.org/10.7208/chicago/9780226924687.001.0001

[7] Committee of on Quality of Health Care in America (2003) Crossing the Quality Chasm. Institute for the Future National Academy Press, Washington DC.

[8] Adedeji, S., Sokol, D.K., Palser, T. and McKneally, M. (2009) Ethics of Surgical Complications. World Journal of Surgery, 33, 732-737. https://doi.org/10.1007/s00268-008-9907-z

[9] Angelos, P. (2009) Complications, Errors, and Surgical Ethics. World Journal of Surgery, 33, 609-611. https://doi.org/10.1007/s00268-008-9914-0

[10] Toyama, N., Kamemori, Y. and Kuwahara, N. (2013) Incident and Accident Hokoku No Suishin to Sono Katsuyo (Japanese Literature). Kango Tenbo, 38, 22-29.

[11] World Health Organization (2008) World Alliance for Patient Safety Progress Report 2006-2007. WHO Press, Geneva.

[12] Ayabe, T., Shinpuku, G., Tomita, M., Nakamura, S., Yokoyama, E., Shimizu, S., 
Okumura, M., Itai, K., Tsuneyoshi, I., Takeshima, H. and Nakamura, K. (2017) Changes in Safety Attitude and Improvement of Multidisciplinary Teamwork by Implementation of the WHO Surgical Safety Checklist in University Hospital. Open Journal of Safety Science and Technology, 7, 22-41. https://doi.org/10.4236/ojsst.2017.71003

[13] Wagner, C. and Van der Wall, G. (2005) Voor een goed begrip, bevordering patientveiligheid vraagt om heldere definities. Medisch Contact, 60, 1888-1891.

[14] Kohn, L.T., Corrigan, J.M. and Donaldson, M.S. (2000) To Err Is Human: Building a Safer Health System. National Academy Press, Washington DC.

[15] Aron, D.C. and Headrick, L.A. (2002) Educating Physicians Prepared to Improve Care and Safety Is No Accident: It Requires a Systematic Approach. Quality \& Safety in Health Care, 11, 168-173. https://doi.org/10.1136/qhc.11.2.168

[16] Zegers, M., de Bruijne, M.C., de Keizer, B., Merten, H., Groenewegen, P.P., van der Wal, G. and Wagner, C. (2011) The Incidence, Root-Causes, and Outcomes of Adverse Events in Surgical Units: Implication for Potential Prevention Strategies. $\mathrm{Pa}$ tient Safety in Surgery, 5, 13. https://doi.org/10.1186/1754-9493-5-13

[17] Anderson, O., Davis, R., Hanna, G.B. and Vincent, C.A. (2013) Surgical Adverse Events: A Systematic Review. The American Journal of Surgery, 206, 253-262. https://doi.org/10.1016/j.amjsurg.2012.11.009

[18] Health Grades Quality Study. Fifth Annual Patient Safety.

[19] Baker, G.R., Norton, P.G., Flintoft, V., Blais, R., Brown, A., Cox, J., Etchells, E., Ghali, W.A., Hébert, P., Majumdar, S.R., O’Beirne, M., Palacios-Derflingher, L., Reid, R.J., Sheps, S. and Tamblyn, R. (2004) The Canadian Adverse Events Study: The Incidence of Adverse Events among Hospital Patients in Canada. CMAJ, 170, 1678-1686. https://doi.org/10.1503/cmaj.1040498

[20] Neale, G., Woloshynowych, M. and Vincent, C. (2001) Exploring the Causes of Adverse Events in NHS Hospital Practice. Journal of the Royal Society of Medicine, 94, 322-330. https://doi.org/10.1177/014107680109400702

[21] Andrews, L.B., Stocking, C., Krizek, T., Gottlieb, L., Krizek, C., Vargish, T. and Siegler, M. (1997) An Alternative Strategy for Studying Adverse Events in Medical Care. The Lancet, 349, 309-313. https://doi.org/10.1016/S0140-6736(96)08268-2

[22] Hollnagel, E. (2004) Barriers and Accident Prevention. Ashgate Publishing Limited, Hampshire.

[23] Gruen, R.L., Jurkovich, G.J., McIntyre, L.K., Foy, H.M. and Maier, R.V. (2006) Patterns of Errors Contributing to Trauma Mortality: Lessons Learned from 2,594 Deaths. Annals of Surgery, 244, 371-380.

[24] Krizek, T.J. (2000) Surgical Error: Ethical Issues of Adverse Events. The Archives of Surgery, 135, 1359-1366. https://doi.org/10.1001/archsurg.135.11.1359

[25] Sarker, S.K. (2003) Courses, Cadavers, and Counsellors: Reducing Errors in the Operating Theatre. BMJ, 27, s109. https://doi.org/10.1136/bmj.327.7418.s109

[26] Gawande, A.A., Thomas, E.J., Zinner, M.J. and Brennan, T.A. (1999) The Incidence and Nature of Surgical Adverse Events in Colorado and Utah in 1992. Surgery, 126, 66-75. https://doi.org/10.1067/msy.1999.98664

[27] Leape, L.L., Brennan, T.A., Laird, N., Lawthers, A.G., Localio, A.R., Barnes, B.A., Hebert, L., Newhouse, J.P., Weiler, P.C. and Hiatt, H. (1991) The Nature of Adverse Events in Hospitalized Patients. Results of the Harvard Medical Practice Study II. The New England Journal of Medicine, 324, 377-384. https://doi.org/10.1056/NEJM199102073240605 
[28] Shanafelt, T.D., Balch, C.M., Bechamps, G., Russell, T., Dyrbye, L., Satele, D., Collicott, P., Novotny, P.J., Sloan, J. and Freischlag, J. (2010) Burnout and Medical Errors among American Surgeons. Annals of Surgery, 251, 995-1000. https://doi.org/10.1097/SLA.0b013e3181bfdab3

[29] Fahrenkopf, A.M., Sectish, T.C., Barger, L.K., Sharek, P.J., Lewin, D., Chiang, V.W., Edwards, S., Wiedermann, B.L. and Landrigan, C.P. (2008) Rates of Medication Errors among Depressed and Burnt out Residents: Prospective Cohort Study. BMJ, 336, 488-491. https://doi.org/10.1136/bmj.39469.763218.BE

[30] Firth-Cozens, J. and Greenhalgh, J. (1997) Doctors' Perceptions of the Links between Stress and Lowered Clinical Care. Social Science \& Medicine, 44, 1017-1022. https://doi.org/10.1016/S0277-9536(96)00227-4

[31] Taylor, C., Graham, J., Potts, H., Candy, J., Richards, M. and Ramirez, A. (2007) Impact of Hospital Consultants' Poor Mental Health on Patient Care. The British Journal of Psychiatry, 190, 268-269. https://doi.org/10.1192/bjp.bp.106.023234

[32] West, C.P., Huschka, M.M., Novotny, P.J., Sloan, J.A., Kolars, J.C., Habermann, T.M. and Shanafelt, T.D. (2006) Association of Perceived Medical Errors with Resident Distress and Empathy: A Prospective Longitudinal Study. JAMA, 296, 1071-1078. https://doi.org/10.1001/jama.296.9.1071

[33] Smetana, G.W., Lawrence, V.A. and Cornell, J.E. (2006) Preoperative Pulmonary Risk Stratification for Noncardiothoracic Surgery: Systematic Review for the American College of Physicians. Annals of Internal Medicine, 144, 581-595. https://doi.org/10.7326/0003-4819-144-8-200604180-00009

[34] Qaseem, A., Snow, V., Fitterman, N., Hornbake, E.R., Lawrence, V.A., Smetana, G.W., Weiss, K., Owens, D.K., Aronson, M., Barry, P., Casey, D.E. Jr., Cross, J.T. Jr., Fitterman, N., Sherif, K.D. and Weiss, K.B. (2006) Clinical Efficacy Assessment Subcommittee of the American College of Physicians. Risk Assessment for and Strategies to Reduce Perioperative Pulmonary Complications for Patients Undergoing Noncardiothoracic Surgery: A Guideline from the American College of Physicians. Annals of Internal Medicine, 144, 575-580.

[35] Johnson, R.G., Arozullah, A.M., Neumayer, L., Henderson, W.G., Hosokawa, P. and Khuri, S.F. (2007) Multivariable Predictors of Postoperative Respiratory Failure after General and Vascular Surgery: Results from the Patient Safety in Surgery Study. Journal of the American College of Surgeons, 204, 1188-1198. https://doi.org/10.1016/j.jamcollsurg.2007.02.070

[36] Gordon, L.A. (1994) Gordon's Guide to the Surgical Morbidity and Mortality Conference. Hanley \& Belfus, Philadelphia.

[37] Pierluissi, E., Fischer, M.A., Campbell, A.R. and Landefeld, C.S. (2003) Discussion of Medical Errors in Morbidity and Mortality Conferences. JAMA, 290, 2838-2842. https://doi.org/10.1001/jama.290.21.2838

[38] Thomas, E.J. and Petersen, L.A. (2003) Measuring Errors and Adverse Events in Health Care. Journal of General Internal Medicine, 18, 61-67. https://doi.org/10.1046/j.1525-1497.2003.20147.x

[39] ElBardissi, A.W., Wiegmann, D.A., Henrickson, S., Wadhera, R. and Sundt, T.M. (2008) Identifying Methods to Improve Heart Surgery: An Operative Approach and Strategy for Implementation on an Organizational Level. European Journal of Cardio-Thoracic Surgery, 34, 1027-1033. https://doi.org/10.1016/j.ejcts.2008.07.007

[40] Rogers, S.O. Jr., Gawande, A.A., Kwaan, M., Puopolo, A.L., Yoon, C., Brennan, T.A. and Studdert, D.M. (2006) Analysis of Surgical Errors in Closed Malpractice Claims at 4 Liability Insurers. Surgery, 140, 25-33. 
https://doi.org/10.1016/j.surg.2006.01.008

[41] Greenberg, C.C., Regenbogen, S.E., Studdert, D.M., Lipsitz, S.R., Rogers, S.O., Zinner, M.J. and Gawande, A.A. (2007) Patterns of Communication Breakdowns Resulting in Injury to Surgical Patients. Journal of the American College of Surgeons, 204, 533-540. https://doi.org/10.1016/j.jamcollsurg.2007.01.010

[42] Christian, C.K., Gustafson, M.L., Roth, E.M., Sheridan, T.B., Gandhi, T.K., Dwyer, K., Zinner, M.J. and Dierks, M.M. (2006) A Prospective Study of Patient Safety in the Operating Room. Surgery, 139, 159-173.

https://doi.org/10.1016/j.surg.2005.07.037

[43] Lingard, L., Espin, S., Whyte, S., Regehr, G., Baker, G.R., Reznick, R., Bohnen, J., Orser, B., Doran, D. and Grober, E. (2004) Communication Failures in the Operating Room: An Observational Classification of Recurrent Types and Effects. Quality \& Safety in Health Care, 13, 330-334. https://doi.org/10.1136/qshc.2003.008425

[44] Arora, S., Hull, L., Sevdalis, N., Tierney, T., Nestel, D., Woloshynowych, M., Darzi, A. and Kneebone, R. (2010) Factors Compromising Safety in Surgery: Stressful Events in the Operating Room. The American Journal of Surgery, 199, 60-65. https://doi.org/10.1016/j.amjsurg.2009.07.036

[45] Rogers, D.A. and Lingard, L. (2006) Surgeons Managing Conflict: A Framework for Understanding the Challenge. Journal of the American College of Surgeons, 203, 568-574. https://doi.org/10.1016/j.jamcollsurg.2006.06.012 